\title{
Near room temperature dielectric transition in the perovskite formate framework $\left[\left(\mathrm{CH}_{3}\right)_{2} \mathrm{NH}_{2}\right]\left[\mathrm{Mg}(\mathrm{HCOO})_{3}\right] \dagger$
}

B. Pato-Doldán ${ }^{a}$, M. Sánchez-Andújar ${ }^{a}$, L. C. Gómez-Aguirre ${ }^{a}$, S. Yáñez$\operatorname{Vilar}^{a}$, J. López-Beceiro ${ }^{b}$, C. Gracia-Fernández ${ }^{c}$, A. A. Haghighirad ${ }^{d}$, F. Ritter $^{d}$, S. Castro-García ${ }^{a}$ and M. A. Señarís-Rodríguez $*^{a}$

${ }^{a}$ Department of Fundamental Chemistry, University of A Coruña, 15071 A Coruña, Spain. Email: tonasr@udc.es; Fax:+34 981167065; Tel: +34981167000

${ }^{b}$ Department of Industrial Engineering II, University of A Coruña, Campus de Esteiro, Ferrol 15403, Spain

${ }^{c}$ Thermal Analysis, Rheology and Microcalorimetry Applications, TA Instruments - Waters

Cromatografía, S.A. Avda. Europa, 21 Parque Empresarial La Moraleja, 28108, Alcobendas Madrid, Spain

${ }^{d}$ Institute of Physics, Goethe University, 60438 Frankfurt am Main, Germany

Physical Chemistry Chemical Physics, 2012, 14, 8498-8501

Received 23rd February 2012, Accepted 8th May 2012

First published on the web 8th May 2012

DOI: $10.1039 / \mathrm{C} 2 \mathrm{CP} 40564 \mathrm{D}$ (Communication)

We report that the hybrid organic-inorganic compound $\left[\left(\mathrm{CH}_{3}\right)_{2} \mathrm{NH}_{2}\right]\left[\mathrm{Mg}(\mathrm{HCOO})_{3}\right]$ shows a marked dielectric transition around $T_{\mathrm{t}} \sim 270 \mathrm{~K}$, associated to a structural phase transition from SG $R \overline{3} c$ (centrosymmetric) to $C c$ (non-centrosymmetric). This is the highest $T_{\mathrm{t}}$ reported so far for a perovskite-like formate that is thus a promising candidate to display electric order very close to room temperature. 
The nanoporous metal-organic frameworks (MOFs) have been extensively studied in the past decade in view of their interesting potential applications, for example, in catalysis and gas storage. ${ }^{1,2}$ In addition to nanoporous MOFs, dense hybrid frameworks are receiving increasing attention as they can display a wide range of interesting functional properties. ${ }^{3,4}$

Among these, the prospects for MOF systems with electrical order are particularly appealing. ${ }^{5}$ In this context, Jain et $a l .{ }^{6}$ have recently reported a series of metal-organic frameworks of formula $\left[\left(\mathrm{CH}_{3}\right)_{2} \mathrm{NH}_{2}\right]\left[\mathrm{M}(\mathrm{HCOO})_{3}\right]$ with $\mathrm{M}^{2+}=\mathrm{Zn}^{2+}, \mathrm{Mn}^{2+}, \mathrm{Co}^{2+}, \mathrm{Ni}^{2+}$ and $\mathrm{Fe}^{2+}$ that belong to this group. In addition, such compounds (except the $\mathrm{Zn}^{2+}$-one) are examples of MOFs with multiferroic behavior, as they also exhibit weak ferromagnetism at low temperatures $\left(T_{\mathrm{C}}=8-36 \mathrm{~K}\right){ }^{6-8}$

These compounds present an $\mathrm{ABX}_{3}$ perovskite architecture, in which the metal cations $(\mathrm{B}=$ $\left.\mathrm{M}^{2+}\right)$ linked by formate groups $\left(\mathrm{X}=\mathrm{HCOO}^{-}\right)$form the $\mathrm{BX}_{3}$ skeleton, and the dimethylammonium (DMA) cations occupy the cavities $\left(\mathrm{A}=\left[\left(\mathrm{CH}_{3}\right)_{2} \mathrm{NH}_{2}\right]^{+}\right)$. These hybrid formates experience a dielectric transition in the temperature range of 160-185 K, depending on the specific M, and DSC detects an associated phase transition that seems to be first order. ${ }^{6,9}$ In the first studies, such transition has been considered of paraelectric-antiferroelectric type in view of the similarities of the ${ }^{\varepsilon_{\mathrm{r}}^{\prime}(T)}$ curve with that of other antiferroelectric materials, ${ }^{10}$ even if more recently it has been claimed that it is associated to the appearance of improper ferroelectricity. ${ }^{5 \mathrm{c}}$ As for the origin of such transition, it has been basically associated to order/disorder of the bridging hydrogen bonds that are formed between the formate framework and the DMA cations. ${ }^{6,11}$

From a practical point of view, the fact that in these compounds such dielectric transition takes place at low temperatures imposes important limitations for potential applications.

In this work we present another hybrid that overcomes this drawback: the perovskite formate framework $\left[\left(\mathrm{CH}_{3}\right)_{2} \mathrm{NH}_{2}\right]\left[\mathrm{Mg}(\mathrm{HCOO})_{3}\right]$.

This $\left[\left(\mathrm{CH}_{3}\right)_{2} \mathrm{NH}_{2}\right]\left[\mathrm{Mg}(\mathrm{HCOO})_{3}\right]$ formate had been previously obtained by Rossin et al., ${ }^{12}$ who described its room-temperature crystal structure together with its $\mathrm{H}_{2}$ and $\mathrm{CO}_{2}$ absorption properties. However, to the best of our knowledge, its dielectric properties have not been reported so far.

We have prepared $\left[\left(\mathrm{CH}_{3}\right)_{2} \mathrm{NH}_{2}\right]\left[\mathrm{Mg}(\mathrm{HCOO})_{3}\right]$ by a different method to that previously reported: ${ }^{12}$ by a solution diffusion technique, which allows the preparation of the pure phase in an easy, direct and reliable way. For this purpose, a $5 \mathrm{ml}$ methanol solution of $0.5 \mathrm{M} \mathrm{HCOOH}$ and $0.5 \mathrm{M}\left(\mathrm{CH}_{3}\right)_{2} \mathrm{NH}$ was placed at the bottom of a glass tube. To this solution $2 \mathrm{ml}$ 
of methanolwere added, followed by layering $8 \mathrm{ml}$ of a methanol solution of $0.10 \mathrm{M} \mathrm{MgCl}_{2}$. Colorless cubic shape crystals with dimensions of around $0.12 \mathrm{~mm}$ were obtained after thirty hours.

Elemental chemical analysis and room temperature powder X-ray diffraction (see Fig. S1a of ESI†े) confirmed the composition and the crystal structure of the obtained $\left[\left(\mathrm{CH}_{3}\right)_{2} \mathrm{NH}_{2}\right]\left[\mathrm{Mg}(\mathrm{HCOO})_{3}\right]$ compound (Fig. 1). According to room temperature single crystal X-ray diffraction data (see ESI†, Tables SI and SII), and in full agreement with the literature, ${ }^{12}$ at this temperature this compound shows $R \overline{3} c$ symmetry. In this structure the metal cation is in a regular octahedral environment, where the $\mathrm{Mg}-\mathrm{O}$ distance is $2.09 \AA$. As for the DMA cations, they are disordered with nitrogen apparently existing in three different possible positions, as it has also been described for other DMA perovskite-like formates; ${ }^{6}$ and the distance between the $\mathrm{N}$ atom and the $\mathrm{O}$ atoms of the closest formate anion $(d \sim 2.93 \AA)$ is short enough to allow the presence of a bridging H-bond between these two atoms, even if the $\mathrm{H}$ atoms could not be located because of the disorder.

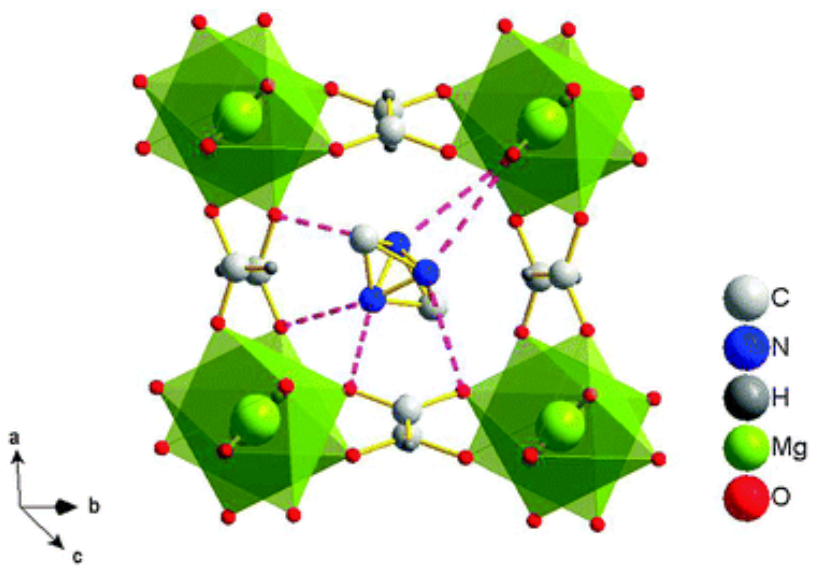

Fig. 1 Conventional perovskite structure view of $\left[\left(\mathrm{CH}_{3}\right)_{2} \mathrm{NH}_{2}\right]\left[\mathrm{Mg}(\mathrm{HCOO})_{3}\right]$ at room temperature. Dashed pink lines indicate the presence of possible $\mathrm{N}^{\cdots \cdots} \mathrm{H}^{\cdots \cdots}$ O bonds.

On the other hand, single crystal X-ray diffraction data collected at $100 \mathrm{~K}$ revealed the presence of additional weaker spots in the precession images generated along the $[h 0 l]$ direction, suggesting the formation of a superstructure and the existence of a temperature induced phase transition. Unfortunately, the low temperature single crystal structural data set could not be solved due to complex twinning of the crystal.

Most interestingly, powder X-ray diffraction (PXRD) experiments carried out at different temperatures confirmed that this compound experiences a structural phase transition as a function of temperature. 
As shown in Fig. 2, the PXRD data obtained at different temperatures clearly show that while at room temperature the only phase present is the one with $R \overline{3} c$ symmetry (phase I), upon cooling a new phase II starts to develop around $270 \mathrm{~K}$.

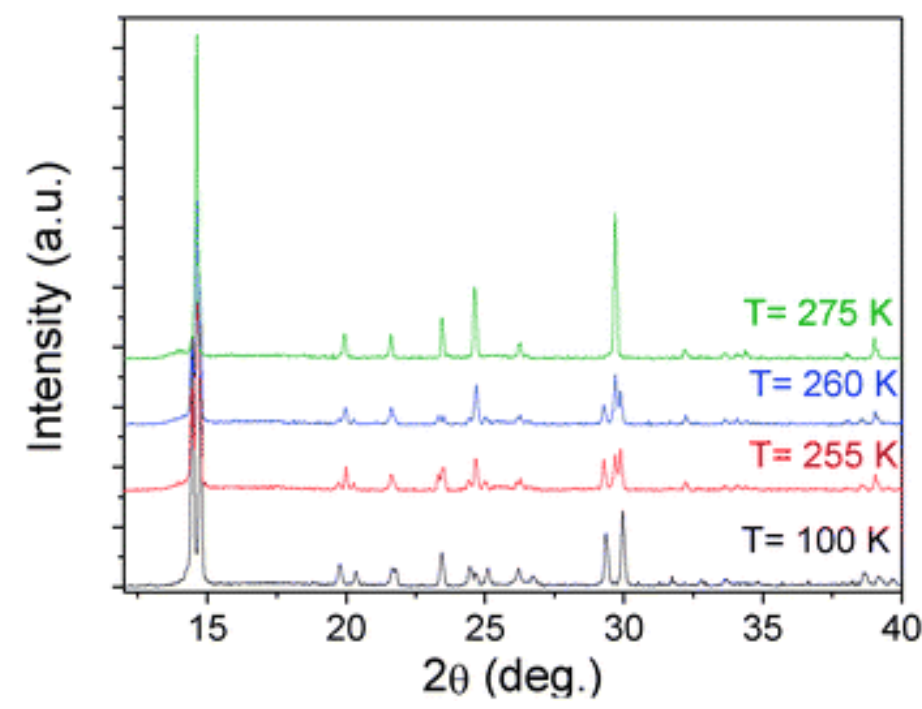

Fig. 2 Powder X-ray diffraction (PXRD) patterns obtained at different temperatures between room temperature and $100 \mathrm{~K}$.

Both phases coexist in the temperature range $170<T(\mathrm{~K})<270$, the amount of phase II increasing as temperature decreases, and finally phase II is the only one detected for $T \leq 170 \mathrm{~K}$ (see ESI†, Fig. S2).

From a Le Bail refinement of the PXRD pattern at $100 \mathrm{~K}$ (see ESI†, Fig. S1b) we obtained that phase II shows a monoclinic structure (space group: $C c$ ) with the following cell parameters: $a=14.0518(8) \quad \AA, b=8.1732(6) \quad \AA, c=8.7629(6) \quad \AA$ and $\beta=120.252(5)^{\circ}$. Therefore, and very interestingly, the low temperature phase (phase II) shows the same structure and non-centrosymmetric space group found for the Mn-compound, $\left[\left(\mathrm{CH}_{3}\right)_{2} \mathrm{NH}_{2}\right]\left[\mathrm{Mn}(\mathrm{HCOO})_{3}\right]$, at $100 \mathrm{~K},{ }^{11}$ even if the cell parameters of the former are slightly smaller, as expected from the smaller size of $\mathrm{Mg}^{2+}$ compared to $\mathrm{Mn}^{2+} .13$

From Le Bail refinements of the rest of the data, we obtained the temperature dependence of the cell parameters of phase I and phase II that is shown in Fig. 3. 


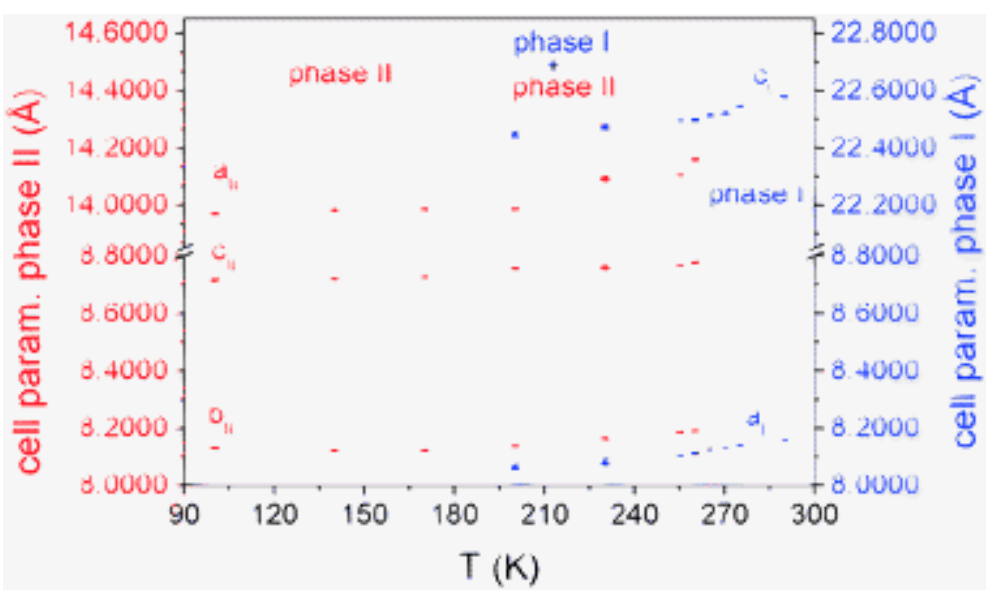

Fig. 3 Evolution of the cell parameters of phases I and II as a function of temperature.

As expected, the cell parameters of both phases appear to increase with temperature, even if in phase I the rise seems to be more pronounced above $250 \mathrm{~K}$.

Unfortunately, further structural data could not be obtained from the PXRD data as marked preferential orientation effects prevented us from obtaining good enough Rietveld refinements (see additional comments in ESI $\dagger$ ).

Differential scanning calorimetric (DSC) experiments made on heating and cooling at different rates also revealed the existence of a phase transition. The different rates did not affect significantly the temperature range at which the process takes place, indicating a non-kinetic behaviour (see ESI†, Fig. S3). A rather acute endothermic transition is seen around $263 \mathrm{~K}$ when heating and an analogous exothermic transition is observed around $258 \mathrm{~K}$ on cooling (Fig. 4). Such thermal behaviour points to a first order transition. The associated changes in enthalpy $\Delta H\left(\mathrm{~J} \mathrm{~mol}^{-1}\right)$ and entropy $\Delta S\left(\mathrm{~J} \mathrm{~mol}^{-1} \mathrm{~K}^{-1}\right)$ were determined from the area under the $C_{\mathrm{p}} / T$ curve obtained at $10 \mathrm{~K} \mathrm{~min}^{-1}$ and the peak temperature, $T_{\max }$. The results yield a $\Delta H \sim 1200 \mathrm{~J}$ $\mathrm{mol}^{-1}$ and $\mathrm{a} \Delta S \sim 4.6 \mathrm{~J} \mathrm{~mol}^{-1} \mathrm{~K}^{-1}$.

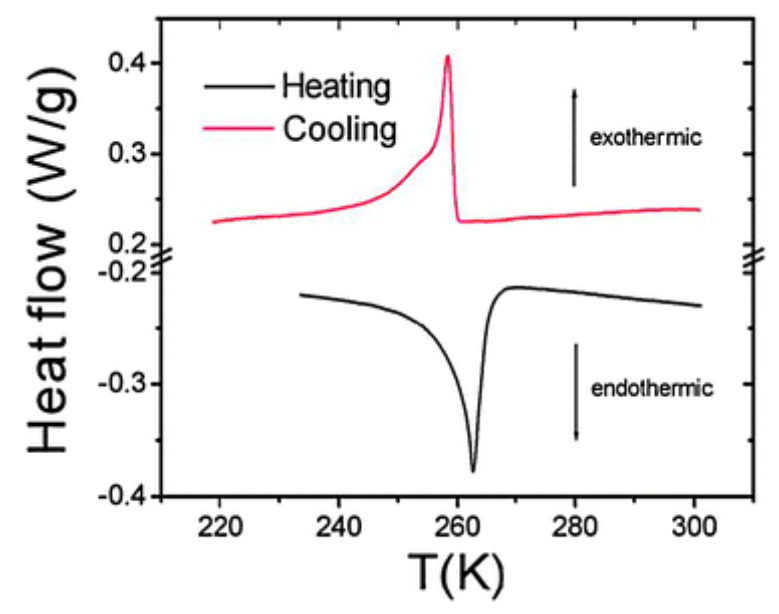

Fig. 4 DSC results as a function of temperature obtained by heating and cooling the sample $\left[\left(\mathrm{CH}_{3}\right)_{2} \mathrm{NH}_{2}\right]\left[\mathrm{Mg}(\mathrm{HCOO})_{3}\right]$ at a rate of $10 \mathrm{~K} \mathrm{~min}^{-1}$. 
Taking into account that for an order-disorder transition $\Delta S=R \ln (N)$, where $R$ is the gas constant and $N$ is the ratio of the number of configurations in the ordered and disordered system, a value of $N \sim 1.7$ is calculated for this compound. This means than the transition is more complex than that described by a simple 3-fold order-disorder model (for which $N=3$ would be expected), ${ }^{6 a}$ as it also occurs in the related $\mathrm{Mn}$ - and Co-formates, ${ }^{6 \mathrm{~b}, 9 \mathrm{a}}$ and in agreement with the progressive transformation observed by PXRD.

We have also measured the Raman powder spectra of this compound at $300 \mathrm{~K}$ and at $100 \mathrm{~K}$ (see ESI $\dagger$, Fig. S4). Very interestingly, significant changes in the frequency, splitting and intensities are observed in certain vibrations ascribed to the DMA cations, while no significant changes are observed in those attributed to the formate anion. This behavior is similar to that previously reported for $\left[\left(\mathrm{CH}_{3}\right)_{2} \mathrm{NH}_{2}\right]\left[\mathrm{Mn}(\mathrm{HCOO})_{3}\right]$, and ascribed to changes in the degree of rotation of the DMA cations inside the perovskite cavities. ${ }^{11}$

In order to find out if the observed phase transition is accompanied by a dielectric transition, we have measured the complex dielectric permittivity ${ }^{\left(\varepsilon_{r}=\varepsilon_{r}^{\prime}-i \varepsilon_{r}^{\prime \prime}\right)}$ of $\left[\left(\mathrm{CH}_{3}\right)_{2} \mathrm{NH}_{2}\right]\left[\mathrm{Mg}(\mathrm{HCOO})_{3}\right]$ as a function of temperature and frequency. Fig. 5a and b show the temperature dependence of the real part of the complex dielectric permittivity (the so-called dielectric constant, ${ }^{\varepsilon_{r}^{\prime}}$ ) and the dielectric losses $(\tan \delta)$. As it can be seen, ${ }^{\varepsilon_{r}^{\prime}}$ experiences a wide dielectric transition between 150 and $270 \mathrm{~K}$. For $T<150 \mathrm{~K}$ its value is low ${ }^{\left(\varepsilon_{\mathrm{r}}^{\prime} \sim 5\right)}$ and frequency independent. Upon heating, ${ }^{\varepsilon_{r}^{\prime}}$ displays a progressive but clear increase of almost one order of magnitude in the temperature interval 150-270 K, showing a strong frequency dependence, pointing to a dielectric relaxation mechanism. In addition, in this temperature interval, the loss tangent goes through a maximum that shifts to higher temperatures as the measuring frequency increases. 


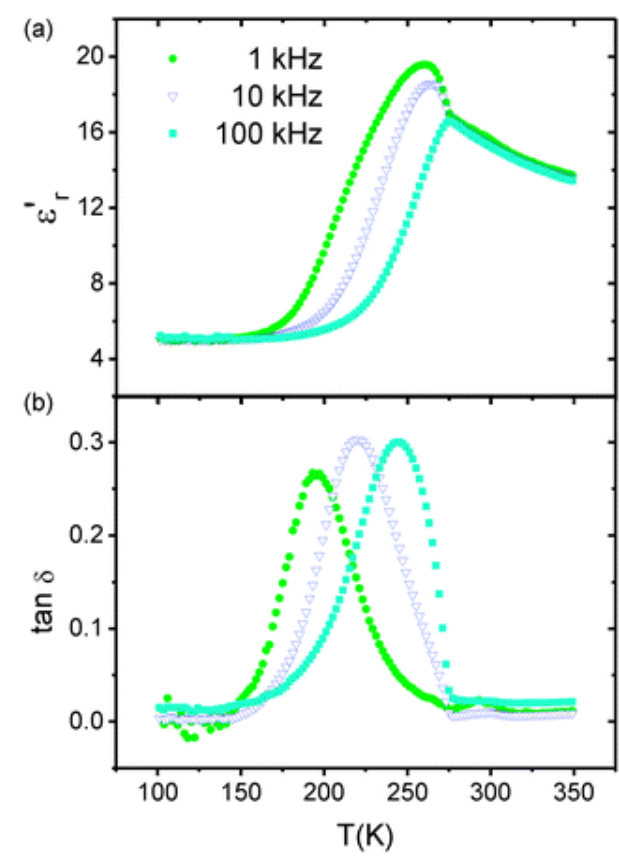

Fig. 5 Temperature dependence of (a) the dielectric constant, ${ }^{\varepsilon_{r}^{\prime}}$, and (b) the dielectric losses, $\tan \delta$, of $\left[\left(\mathrm{CH}_{3}\right)_{2} \mathrm{NH}_{2}\right]\left[\mathrm{Mg}(\mathrm{HCOO})_{3}\right]$ measured at different frequencies (1-100 $\mathrm{kHz})$.

For $T>270 \mathrm{~K},{ }_{r}^{\varepsilon_{r}^{\prime}}$ decreases slightly as the temperature rises and is frequency independent, as expected for a paraelectric behavior.

On the other hand, and taking into account that the presence of trace amounts of water on the surface of the crystals, or even on the electrodes, could result in the appearance of artifacts in the dielectric measurements in the room temperature region ${ }^{14}$ we have made additional studies to make sure that the observed signal really comes from the sample.

For this purpose, and to avoid misinterpreting results ${ }^{15,16}$ we have performed impedance complex plane $\left(Z^{\prime \prime} v s . Z^{\prime}\right)$ analysis of the data obtained at different temperatures. A typical impedance complex plane plot for this sample in the whole temperature interval $110-350 \mathrm{~K}$ is shown in Fig. 6.

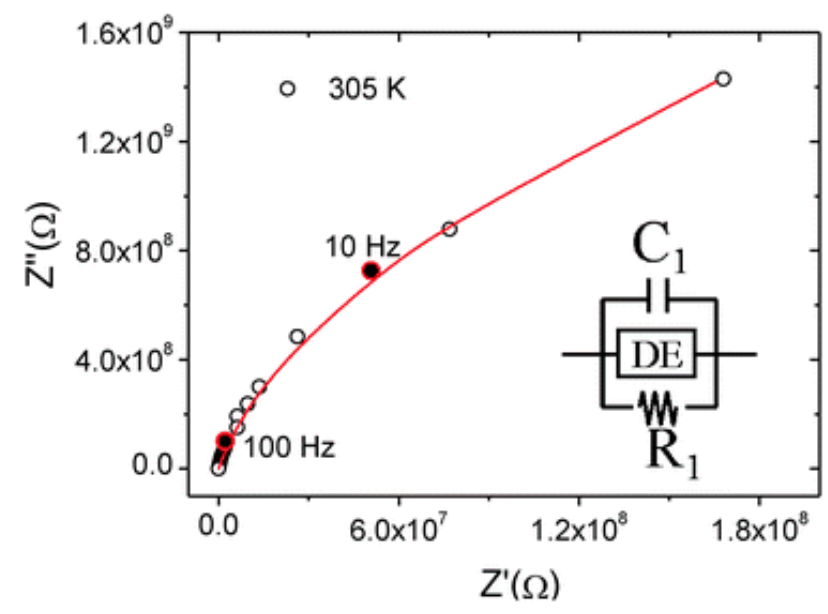

Fig. 6 Typical impedance complex plane diagram of $\left[\left(\mathrm{CH}_{3}\right)_{2} \mathrm{NH}_{2}\right]\left[\mathrm{Mg}(\mathrm{HCOO})_{3}\right]$ and its corresponding fit representative of all the temperature $(110-350 \mathrm{~K})$ and frequency ranges $(1 \mathrm{~Hz}-1 \mathrm{MHz})$. 
As it can be seen, it shows a single large arc that can be modeled by an equivalent circuit containing three elements connected in parallel: a resistance $(\mathrm{R})$, a capacitance (C) that is frequency independent, and a frequency-dependent distributed element (DE). As this large arc intercepts zero and the order of magnitude of its capacitance is of $\mathrm{pF} \mathrm{cm}$, it is associated with the material bulk response. ${ }^{15}$ Taking into account that this is the only contribution present, we concluded that the observed dielectric response is purely intrinsic in the whole temperature interval. This result confirms that the observed dielectric transition is real and associated to the material's bulk response.

With all this information in hand, and as in the case of the $\mathrm{Mn}^{2+}$-compound, ${ }^{11}$ we attribute the dielectric transition reported here to the dynamics of the DMA cations inside the cavities. For $T>270 \mathrm{~K}$ the paraelectric behavior would be due to the rotation of the DMA cations, which can occur because at those temperatures the thermal energy is able to overcome the strength of the weak hydrogen bonds between the DMA and the $\mathrm{Mg}^{2+}$-formate framework. As temperature decreases, the rotation of the DMA cations progressively slows down until it finally freezes completely at low temperature. Taking into account that the shape of the curve is very similar to that of relaxors, ${ }^{17}$ we attribute the dielectric relaxation observed to a rather progressive freezing process, that does not take place simultaneously in the whole sample, as revealed by the coexistence of phase I and phase II in this temperature interval.

A specially interesting issue is why in this $\mathrm{Mg}^{2+}$-compound such transition takes place at a considerably higher temperature than in the case of its $\mathrm{Mn}^{2+}, \mathrm{Fe}^{2+}, \mathrm{Co}^{2+}, \mathrm{Ni}^{2+}$ and $\mathrm{Zn}^{2+}$ analogues (where $T_{\mathrm{t}} \sim 160-185 \mathrm{~K}$ ). We attribute this difference to the influence of the $\mathrm{M}^{2+}$ cations on the structural and electronic characteristics of the $\mathrm{M}(\mathrm{HCOO})_{3}{ }^{-}$framework with whom the DMA cations form H-bonds, which are the underlying cause of the observed behavior. In this context, the fact that the $\mathrm{Mg}^{2+}$ ion is a harder Lewis acid than $\mathrm{Mn}^{2+}, \mathrm{Fe}^{2+}, \mathrm{Co}^{2+}, \mathrm{Ni}^{2+}$ and $\mathrm{Zn}^{2+}$ ${ }^{18}$ results in the case of $\mathrm{M}^{2+}=\mathrm{Mg}^{2+}$ in more ionic metal-oxygen bonds and in a more localized negative charge in the $\mathrm{O}$ atoms of the formate anions. As a consequence, the $\mathrm{O}$ atoms of the $\mathrm{Mg}^{2+}$-formate form stronger $\mathrm{H}$-bonds with the DMA cations, which are stable up to higher temperatures.

In conclusion, we report that the $\left[\left(\mathrm{CH}_{3}\right)_{2} \mathrm{NH}_{2}\right]\left[\mathrm{Mg}(\mathrm{HCOO})_{3}\right]$ compound displays a dielectric transition near room temperature, $T_{\mathrm{t}} \sim 270 \mathrm{~K}$, the highest $T_{\mathrm{t}}$ reported so far for a perovskite-like formate. This dielectric transition is associated to a structural phase transition from SG $R \overline{3}$ $c$ to $C c$, the latter phase displaying the same non-centrosymmetric group, and very likely the same structure, found for the low temperature phase of the Mn-formate, ${ }^{11}$ in which the cooperatively ordering of the DMA cations inside the cavities gives rise to a polar structure. Therefore $\left[\left(\mathrm{CH}_{3}\right)_{2} \mathrm{NH}_{2}\right]\left[\mathrm{Mg}(\mathrm{HCOO})_{3}\right]$ is the first dense MOF compound with perovskite 
structure that is a promising candidate to display electric order very close to room temperature. This finding will surely facilitate new experiments that shed more light on these interesting phenomena that can occur in dense MOF materials. Furthermore, it will boost the research on these compounds in order to design new structures which can be useful for technological applications.

\section{Acknowledgements}

The authors are grateful for financial support from Ministerio de Economia y Competitividad MINECO (Spain) under project FEDER MAT2010-21342-C02-01 and from Xunta de Galicia under project PGIDIT10PXB103272PR. B.P.-D. also wants to thank MINECO for a FPI fellowship. A. Llamas from Unidad de rayos X (USC) is acknowledged for his efforts with the single crystal X-ray diffraction data.

\section{Notes and references}

1. O. M. Yaghi, M. O'Keeffe, N. W. Ockwig, H. K. Chae, M. Eddaoudi and J. Kim, Nature, 2003, 423, 705

2. A. J. Fletcher, K. M. Thomas and M. J. Rosseinsky, J. Solid State Chem., 2005, 178, 2491

3. A. K. Cheetham and C. N. R. Rao, Science, 2007, 318, 58

4. G. Ferey, Chem. Soc. Rev., 2008, 37, 191

5. (a) M. Guo, H. L. Cai and R. G. Xiong, Inorg. Chem. Commun., 2010, 13, 1590; (b) T. Hang, H. Y. Ye and R. G. Xiong, Chem. Soc. Rev., 2011, 40, 3577; (c) W. Zhang and R. G. Xiong, Chem. Rev., 2012, 112, 1163 (and references therein).

6. (a) P. Jain, N. S. Dalal, B. H. Toby, H. W. Kroto and A. K. Cheetham, J. Am. Chem. Soc., 2008, 130, 10450 ; (b) P. Jain, V. Ramachandran, R. J. Clark, H. D. Zhou, B. H. Toby, N. S. Dalal, H. W. Kroto and A. K. Cheetham, J. Am. Chem. Soc., 2009, 131, 13625

7. (a) X. Y. Wang, L. Gan, S. W. Zhang and S. Gao, Inorg. Chem., 2004, 43, 4615; (b) P. J. Baker, T. Lancaster, I. Franke, W. Hayes, S. J. Blundell, F. L. Pratt, P. Jain, Z.-M. Wang and M. Kurmoo, Phys. Rev. B: Condens. Matter, 2010, 82, 012407

8. Z. Wang, K. Hu, S. Gao and H. Kobayashi, Adv. Mater., 2010, 22, 1526

9. (a) A. W. Fu, W. Zhang, H. L. Cai, Y. Zhang, J. Z. Ge, R. G. Xiong, S. D. Huang and T. Nakamura, Angew. Chem., Int. Ed., 2011, 50, 11947; (b) J. López-Beceiro, C. Gracia- 
Fernández, S. Gómez-Barreiro, S. Castro-García, M. Sánchez-Andújar and R. Artiaga, J. Phys. Chem. C, 2012, 116, 1219

10. M. E. Lines and A. M. Glass, Principles \& applications of Ferroelectric \& related materials, Oxford University Press, New York, 2001

11. M. Sánchez-Andujar, S. Presedo, S. Yáñez-Vilar, S. Castro-García, J. Shamir and M. A. Senarís-Rodríguez, Inorg. Chem., 2010, 49, 1510

12. (a) A. Rossin, A. Ienco, F. Costantino, T. Montini, B. Di Credico, M. Caparoli, L. Gonsalvi, P. Fornasiero and M. Peruzzini, Cryst. Growth. Des., 2008, 8, 3302; (b) A. Rossin, D. Fairen-Jimenez, T. Düren, G. Giambastiani, M. Peruzzini and J. G. Vitillo, Langmuir, 2011, 27, 10124

13. R. D. Shannon and C. T. Prewitt, Acta Crystallogr., Sect. B: Struct. Crystallogr. Cryst. Chem., 1969, 25, 925

14. E. Barsoukov and J. R. Macdonald, Impedance spectroscopy: theory, experiment, and applications, John Wiley \& Sons, New Jersey, 2005

15. D. C. Sinclair, T. B. Adams, F. D. Morrison and A. R. West, Appl. Phys. Lett., 2002, 80, 2153

16. (a) J. F. Scott, J. Phys.: Condens. Matter, 2008, 20, 21001; (b) A. Loidl, S. Krohns, J. Hemberger and P. Lunkenheimer, J. Phys.: Condens. Matter, 2008,20, 19100

17. G. A. Samara, J. Phys.: Condens. Matter, 2003, 15, R367

18. C. E. Housecroft and A. G. Sharpe, Inorganic Chemistry, Pearson Education limited, London, 2008

\section{Footnote}

$\uparrow$ Electronic supplementary information (ESI) available: Experimental details and results of Le Bail refinement of powder X-ray diffraction, details of single-crystal X-ray diffraction, elemental analysis, DSC curves and Raman spectra. See DOI: 10.1039/c2cp40564d 